\title{
Entrepreneurship and the Strategic Transformation of Medium and Small Enterprises
}

\author{
Yuanqing Shen ${ }^{1, a}$,Zhijiang Liu $^{2, b}$ \\ ${ }^{1}$ Management School, Jinan University, Guangzhou 510632, China \\ ${ }^{2}$ International Business School, Jinan University, Guangzhou 510632, China \\ a hewitt_ada@126.com, ${ }^{\mathrm{b}}$ Izj110100@sina.com
}

Keywords: Entrepreneurship, Strategic transformation, Medium and small enterprises, Enterprise strategy

\begin{abstract}
In this article, the study on the relationship between entrepreneurship and the strategic transformation of medium and small enterprises leads to the conclusion that the former has an impact on the latter. To be more specific, since entrepreneurship helps to distinguish opportunities and threats, such sharp insight and adventure provide enterprises with grounds when deciding whether to have strategic transformation; such a decisive role can be revealed in Chinese entrepreneurs' profit-oriented and blundering spirits; entrepreneurship, especially their initiative, talent awareness, devotion and cooperation, is the key factor for the implementation of enterprises' strategies. Therefore, for the entrepreneurs in Chinese medium and small enterprises, it is of particular importance to improve psychological and spiritual personality, to overcome restlessness and practicality, to develop a long-term view and crisis awareness, to respect, make full use of and cultivate talents, hence promoting their strategic transformation, improving their competitiveness and grasping the high end of the global industrial chain with a down-to-earth spirit and a cooperative attitude.
\end{abstract}

\section{Introduction}

With the development of global economy, medium and small enterprises are faced with increasingly challenging competition, along with the cancellation of preferential taxation policies by the government after China's entry into WTO. Long-term excessive supply, fast updating of technological innovation, varying market preferences, increasingly complex environment for enterprises' competition and higher degree of uncertainty confront present enterprises. In such a case, it is impossible to expect an ever-lasting advantage in competition. Only through constant transformation and reform to establish dynamic competitiveness can they find a way for survival and development.

At the end of 2010, it was revealed in the report Survey and Suggestion on Medium and Small Enterprises' Transformation and Innovation in the Post-Crisis Era issued by CDNCA that Chinese medium and small enterprises have only an average survival span of 3.7 years, compared with 12.5 years among Japanese ones, 8.2 years among American ones, and even over 100 years among 1/4 of 500 medium and small enterprises in Germany.

A complicated set of reasons can explain such a phenomenon, including the shortage of effective support and perfect environment compared with other nations. Therefore, only by seizing the opportunities for development to have reform and strategic transformation with an adventurous and cautious attitude can they survive and develop.

In these enterprises, it is not unusual that the employer or a senior manager can be super-powerful to dominate everything. The property right, scale, organizational structure and institution of these enterprises make the role of entrepreneurs, who have a significant influence during the transformation process, particularly important. 


\section{Literature Review}

\subsection{The Definition of Entrepreneurship}

The connotation of entrepreneurship has long been the focus of domestic and foreign scholars, which hasn't been given a universally-accepted and standard definition by various scholars from diverse perspectives. To sum up, there are mainly three following kinds of theories.

\subsubsection{The Trait Theory}

The study based on the trait theory has gone through a process from individual entrepreneurs to groups and has summarized the connotation of entrepreneurship and emphasized some issues on who entrepreneurs are and what the characteristic of entrepreneurship is by analyzing some universal features displayed in this group. Represented by Joseph Alois Schumpeter, Knight, Milx Weber and Albert Otto Hirschman, researchers point out that initiative, adventure, devotion and cooperation are significant dimensions of entrepreneurship. Among them, initiative is the soul of entrepreneurship, the lack of which is the most serious risk for an enterprise; adventure is the nature of entrepreneurship, with which they can be the first to try innovation (Mao, 2009); devotion, the motivation for entrepreneurship, means diligence, loyalty, hardship and ambition; cooperation is the essence of entrepreneurship since collective acts are the key to the coordinative development of enterprises instead of individual ones.

2.1.2 The Behavior Theory

Represented by Gartner, Drueker and Miller, behaviorist scholars reshape entrepreneurship from the behavior perspective and claim that what entrepreneurs really do is the nature of entrepreneurship. This theory has undergone a process from studying entrepreneurs' behavior (reflection, reasoning, balancing and guiding behavior) to studying the behavior of enterprises (innovation, risk taking, lead ship in action and so on).

\subsubsection{The Social Function Theory}

According to this theory, entrepreneurship is a social phenomenon as well as the expanded entrepreneurship in the social area. Davidson (2003), the most important representative, thinks that entrepreneurship is not only the characteristic of individual entrepreneurs but a social phenomenon formed by such a special group in business activities under the regulation of economic institutions in human and social environment. Meanwhile, it is a comprehensive spirit and character centering initiative, motivated by devotion and supported by the courage to take risks (Davidson, 2003).

Taking into consideration the variety of definitions of entrepreneurship made by foreign and domestic scholars, we can find that they have some factors in common despite different manifestations which can be summarized as initiative, devotion, adventure and cooperation. I believe that entrepreneurship should not only derive from entrepreneurs but enterprises and the whole economic society regardless of its source from individuals.

\subsection{Entrepreneurship, Economic Growth and Corporate Performance}

Among the researches conducted in other countries, Schumpeter (1921) first introduced innovation to entrepreneurship due to the central role of innovation in it. Starting from this perspective, he claimed that the changes in the long-term economic cycle are caused by the invention and innovation of enterprises, and basically, by the cyclicity of the innovation process (Ding, 2010). Delong (1988) introduced the spiritual variable to the productive function model, finding an apparent regression coefficient between entrepreneurship and economic growth mainly based on the history of global economic growth from 1870 to 1979 in the last century. Besides, David B. Audretsch and Max Keilbach (2005) conducted an empirical research on the data from 327 regions in Western Germany between 1992 and 2000 with the regression model of productive function the growth equation, drawing the conclusion that there is a positive correlation between entrepreneurship and productivity and the former can therefore promote the growth of regional economy (Audretsch, 2005).

Meanwhile, many domestic economic researches also focus on the impacts of entrepreneurship on economic growth. Xing Li (2011) divides entrepreneurship into two dimensions - adventure entrepreneurship and initiative entrepreneurship, applies the regression equation to his research, 
controls other factors such as population and institution and finally reaches the conclusion that both types of entrepreneurship have positive correlation with economic growth (Li, 2011). Yu Yang, Chuiyong Zheng (2007) utilizes the typical correlation method to have quantitative analysis on entrepreneurship and the growth of regional economy. It is revealed in their research that they have obvious positive correlation with each other. Therefore, through cultivating entrepreneurship and developing private enterprises can regional economy growth be sustained (Yang, 2007).

As is mentioned above, a majority of foreign and domestic literature agree with entrepreneurship's correlation with corporate performance, especially financial performance. It is revealed in Zahra and Covin's research (1995) that the more input is given to the development of entrepreneurs' spiritual activities, the better long-term financial performance will an enterprise have. Meanwhile, according to Franko's study (1989), an enterprise's long-term expense on research and development is positively correlated with its financial performance (Franko, 1989). In this article, normative analysis and empirical data analysis are employed as research methods.

\section{The Relationship between Entrepreneurship and the Strategic Transformation of Medium and Small Enterprises}

\subsection{Enterprises: The Main Body of Transformation}

Just like that of entrepreneurship, the definition of entrepreneurs varies from scholar to scholar. But with the development of social economy and institution, entrepreneurs should not only be confined to different ranks but be given different functions. In order to clearly limit the main body of the research in this article, the definition is given in the following way: developing an enterprise with their functions especially the innovative function with the centre on business activities and being committed to risks at the same time, mainly referring to the director and other members of the board, managers, associate managers, chief engineers, chief economists and other senior executives and owners. In accordance with this definition, what role do entrepreneurs play in the transformation process?

Table 1shows the data on the ultimate decision makers in enterprises obtained in a survey on the current situation of Chinese enterprises' strategies conducted by the Chinese entrepreneur investigation system.

Table 1 Who Ultimately Make the Decisions?

\begin{tabular}{cccccc}
\hline & Chairman/CEO & $\begin{array}{c}\text { Supervision } \\
\text { Department }\end{array}$ & $\begin{array}{c}\text { Board of } \\
\text { Directors }\end{array}$ & Managers & $\begin{array}{c}\text { Party } \\
\text { organization }\end{array}$ \\
\hline Total & 45.7 & 5.7 & 38.3 & 9.4 & 0.9 \\
\hline Large-scale & 19.5 & 17.7 & 49.3 & 9.5 & 4.0 \\
\hline Medium-scale & 41.7 & 6.0 & 42.9 & 8.5 & 0.9 \\
\hline Small-scale & 54.2 & 3.3 & 32.1 & 10.0 & 0.4 \\
\hline State-owned & 12.7 & 35.3 & 17.5 & 28.3 & 6.2 \\
\hline Private-owned & 72.4 & 0.7 & 16.2 & 10.1 & 0.7 \\
\hline Incorporated companies & 39.1 & 4.1 & 50.2 & 6.4 & 0.1 \\
\hline Fimited liability companies & 47.1 & 2.3 & 43.2 & 7.1 & 0.2 \\
\hline Companies & 49.7 & 3.7 & 42.6 & 3.5 & 0.5 \\
\hline Private enterprises & & & & 6.9 & 0.2
\end{tabular}

According to Table 1, in terms of scale, large, medium and small enterprises account for $8.7 \%$, 44.1\% and 47.2\% respectively (among 5016 valid questionnaires); in terms of position, $61.7 \%$ of them are directors, $57.6 \%$ are general managers, $7.3 \%$ factory managers, $16.4 \%$ secretaries, others 5.7\%. (Due to cross specialty and dual positions, the total exceeds 100\%) (Wu, 2010).

As is shown in the survey, two main bodies making the final decisions are the director/ general manager and the board of directors, with the former's role reflected in $45.7 \%$ of the surveyed enterprises and the latter in $38.3 \%$ of them ( $84 \%$ in total). Nearly half of the medium and small 
enterprise give their final decisions to their directors or general managers $(41.7 \%$ among medium enterprises and $54.2 \%$ among small ones), which is far greater than the proportion among large enterprises. $42.9 \%$ of the surveyed medium enterprises and $32.1 \%$ of the small ones give their final decision s to their boards of directors.

Obviously, in medium and small enterprises, most strategic decisions are made by directors, general managers or members of the board, that is to say, one or more very important individuals.

\subsection{Entrepreneurship and Strategic Transformation}

For an enterprise faced with strategic transformation, first, there should be necessity and opportunity for strategic transformation; second, the team led by entrepreneurs should be aware of the necessity of strategic transformation. If dramatic changes happen to the external and internal environment of an enterprise, current strategies are no longer applicable and even hinder its survival. There will be no strategic transformation without such awareness. Therefore, the whole process of strategic transformation comes from the demands for such transformation and covers examination, judgment, choice and planning of strategies, followed by mobilization, implementation and evaluation, hence achieving core competitiveness. Such a whole process cannot be fulfilled spontaneously without the launching, leadership and management of entrepreneurs. Apparently, entrepreneurs' values, patterns of thought and spiritual qualities influence the whole process. According to the relationship between the two, a model related to them is established (Figure 1).

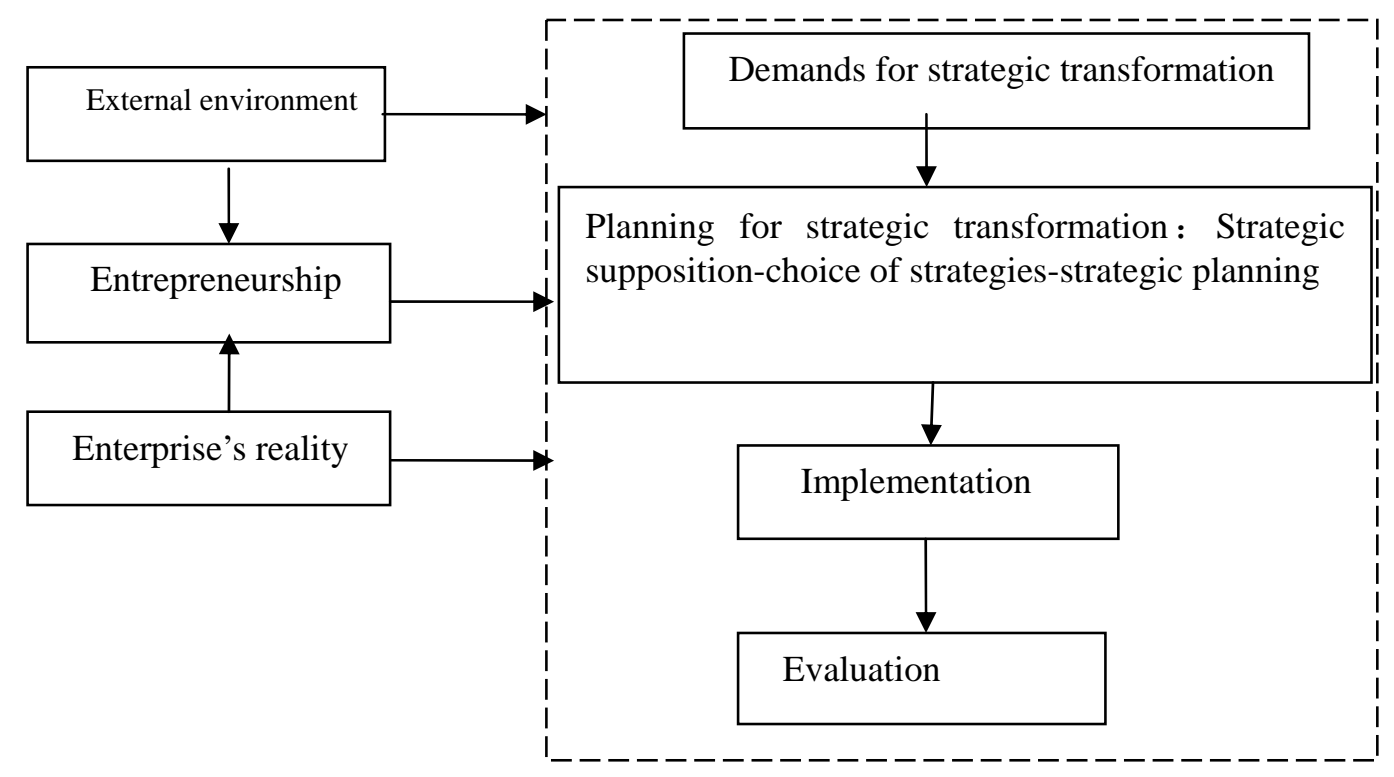

Fig. 1 Model of Entrepreneurship and Strategic Transformation

\subsection{The Influence of Entrepreneurship on Strategic Transformation}

As is pointed out by Yunshi Mao and Yao Wu in their book entitled Chinese Enterprises: Transformation and Upgrading, entrepreneurship is the fundamental force pushing enterprises' transformation and upgrading (Mao, 2009). Many successful instances listed in this book derive from entrepreneurship to a large degree. For instance, in Taiwan where entrepreneurship is vigorous, LED's relevant industries have got intensive attention from entrepreneurs and have formed an industrial alliance with certain scale and mass effect. In this article, it is believed that entrepreneurship has greater influences on the strategic transformation of their enterprises.

First, entrepreneurship strengthens the recognition of the demands for strategic transformation. Entrepreneurs cannot wait until their strategies are no longer fit for environment, resources and capacity. Instead, demands should be revealed at the initial period of crisis or even prior to that, which is the awareness of crisis. Such awareness results from enterprises' insight and judgment to some extent. To be more precise, these should interweave and interact with each other. Any enterprise with the awareness of crisis and far sight should have the capacity to take the lead, to establish strategies conforming to enterprises' development. Such awareness cannot arise 
spontaneously, without which an entrepreneur cannot recognize challenges and opportunities in changes, cannot form his crisis awareness and therefore cannot make demands for strategic transformation.

Second, entrepreneurship determines the direction of strategic transformation. Entrepreneurship is so multi-dimensional that its decisive role can be shown in various dimensions, such as different choices made by conservative and adventurous entrepreneurs, far-sighted and short-sighted ones, entrepreneurs with the sense of social responsibilities and those selfish ones. Despite their insight into opportunities, seize of opportunities and adventurous spirits, they are lacking in far sight and perseverance, thought and behavior related to their causes. In real practice, the profit-oriented entrepreneurship among Chinese entrepreneurs has exerted huge impacts on the direction of Chinese enterprises' strategic transformation.

\section{Conclusion}

Innovation is the most critical and fundamental factor for an enterprise and even a nation. With the increase in global competition, the rising costs in resources and labor forces, the emergence of other developing countries as well as global industrial upgrading brought about by the post-crisis era, the advantages in China's manufacturing industry have disappeared gradually. We will be faced with decline if we don't turn to transformation and innovation. Medium and small enterprises, the main body of China's economic development, serve as the most important force pushing strategic transformation, showing obvious and strong motivation for such a trend. In this process, entrepreneurs, taking a significant and special role, are the main body of their strategic transformation. Through its research on the relationship between entrepreneurship and the strategic transformation of medium and small enterprises, this article finds out that the two have strong relativity in which entrepreneurship enhances these enterprises' demands for transformation, influences relevant decisions and promotes its implementation.

\section{References}

[1] Audretsch, D.M. Keilbach. Entrepreneurship Capital and Regional Growth. The Annals of Regional Science. Vol. 39 (2005), p. 457-469.

[2] Davidsson P, Honig B. The Role of Social and Human Capital among Nascent Entrepreneurs. Journal of Business Venturing. Vol. 18(2003), p.301-331.

[3] Ding, Donghong. Entrepreneurship. Beijing. (2010). p 173-180.

[4] Franko L.G. Global Corporate Competition: Who's Winning, Who's Losing, and the R\&D Factor as One Reason Why. Strategic Management Journal. Vol. 10(1989), p 449-474.

[5] Li, Xing. On the Effect of Enterpreneurship on China's Economic Growth: An Empirical Research Based on SYS-GMM. Science Research Management. (2011).

[6] Mao, Yunshi and Wu, Yao. Chinese Enterprises: Transformation and Upgrading. Guangzhou: (2009).

[7] Wu, Yajun. Chinese Enterprises’ Strategies---Reality, Problems and Suggestions: A Report on the Growth and Development of Chinese Venturers in 2010. Beijing. (2010).Chinese Entrepreneurs Survey System.

[8] Yang, Yu. Zheng, Chuiyong. Typical Relevance Analysis on Enterpreneurship and Regional Economic Growth. Industrial Technology \& Economy. (2007). 